\title{
EXAMINING SOCIAL ADJUSTMENT OF COLLEGE STUDENT-ATHLETES
}

\author{
Mary Jo Self $1 \bowtie(D$, Nick Anthony Stowers $2 \square$ (i) \\ ${ }^{1}$ Associate Professor, Tuttle Endowed Chair, College of Education and Human Sciences, Oklahoma State \\ University, Tulsa, OK, USA. \\ ${ }^{2}$ Assistant Professor, Department of Kinesiology, East Central University, Ada, OK, USA
}

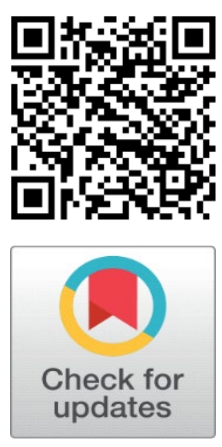

Received 15 November 2021

Accepted 01 December 2021

Published 31 January 2022

\section{CorrespondingAuthor}

Mary Jo Self,

maryjo.self@okstate.edu

DOI

10.29121/granthaallayah.v10.i12.202 2.4419

Funding: This research received no specific grant from any funding agency in the public, commercial, or not-for-profit sectors.

Copyright: (C) 2022 The Author(s). This is an open access article distributed under the terms of the Creative Commons Attribution License, which permits unrestricted use, distribution, and reproduction in any medium, provided the original author and source are credited.

\section{ABSTRACT}

The college experience is an important aspect of a student's success in college. For student-athletes, there are additional pressures to maintain eligibility while competing in their sport. This study examines the social adjustment of student-athletes at the Division II level. The research explores differences that might exist in student-athletes and non-athletes in the area of social adjustment. In addition, differences in college adjustment between males and females are considered. For this study, 138 Student Adaptation to College Questionnaires (SACQ) were completed by student-athletes and non-athletes at two regional universities in Oklahoma. Only social adjustment scores were analyzed to identify the social adjustment of student-athletes. Findings revealed gender and athletic status were strongly associated with college adjustment. Implications and recommendations for future research are discussed.

Keywords: Sport, Athlete Development, Adult Education, Collegiate Athletics, Adjustment, Athletic Participation

\section{INTRODUCTION}

College adjustment is complex and includes several academic, social, personal/emotional, and institutional attachment/goal commitment factors. In essence, integration into the college environment is a direct predictor of a student's decision to stay or leave college Tinto (1993). The commitment to educational goals at an institution may lead to the student's likelihood of persisting in the college environment, leading to a positive outcome Tinto (1993). If these factors are successfully navigated and students adjust to the new environment, the likelihood of higher overall college retention exists (Baker \& Syrik, 1984), Baker and Siryk (1999). While research indicates that student adjustment is related to academic performance and graduation Melendez (2006), less is known about the relationship between college student adjustment and the student-athlete experience, or if the adjustment for intercollegiate athletes differs from the adjustment of non-athletes. The pressures of simultaneously maintaining academic eligibility, while successfully performing on the field or court might seem particularly daunting for student-athletes trying to adjust to college.

Particular interest in the student-athlete population has recently surfaced, likely due to overwhelming media coverage of college sports, as well as the high demands placed on these athletes. Being a student-athlete can be challenging, as the struggle with newly discovered independence, development of new social groups, and planning for life after athletics, all of which occur at the same time Jordan and Denson (1990). Student-athletes can also develop overwhelming

\footnotetext{
How to cite this article (APA): Self, M. J., and Stowers, N., Examining Social Adjustment of College Student-Athletes. International Journal of Research - GRANTHAALAYAH, 10(1), 9-20. doi: 10.29121/granthaalayah.v10.i12.2022.4419
} 
feelings of isolation and stress as they adjust to the new athletics culture, requiring a rigorous schedule of practices, team meetings, and class attendance. To help with these demands, student-athletes are provided with a strong support system that helps them monitor progress and stay on track. Life skills programs (including leadership development) and athletic academic advisors are some of those support systems NCAA (2016). It is possible though that these demands can also help to build resiliency and may allow student-athletes to become more tolerant of the changes in their lives Freeman (2009).

While support programs do exist, it is important to identify ways of easing the transition to college life for student-athletes and non-athletes. As students adjust to the changes in their collegiate lives, hopefully the adjustment will be such that the student decides to stay at the institution. Failure to adjust to the changes makes it more likely the student will discontinue college or change institutions. It is the desire of the institution to retain these students and strategies have been implemented to that effect. As these strategies are considered, colleges and universities have identified the cumulative college experience as a major factor in the success and graduation of students McFarlane (2014); Thomas (2002). This cumulative experience, composed of institutional, personal and social attributes, is fundamentally important to the success and retention of the student McFarlane (2014); Thomas (2002). Retention is an evolving topic of concern as interpretations of student retention have altered the role that the campus environments play in students' decisions to stay or leave the institution (Tinto, 2016).

All students are faced with adjustment demands and must develop strategies of adaption as they enter the new and unfamiliar college environment. Strategies of adaptation are developed, which are positive and negative. While athletic participation certainly provides challenges for the student-athletes, it can also positively impact the character of the student-athlete above and beyond the typical college experience. Carodine et al. (2001) identified the skills student-athletes gain while meeting the demands of athletic eligibility, such as career decision making, establishing personal values, creating relationships, developing self-esteem and integrity, and gaining interdependence and autonomy, in addition to the high level of commitment and opportunity to earn a degree while participating in intercollegiate sports.

Part of the adjustment process for the athlete is the development of "athletic identity." Brewer et al. (1993) believe athletic identity is composed of both positive and negative factors. The degree to which an individual identifies with the role of an athlete is known as athletic identity. However, when athletes no longer perform, this identity may cease to exist and could possibly affect their experience and retention. As indicated by Melendez (2006), sport performance and self-esteem were linked together in individuals who have developed a strong athletic identity, placing highly perceived importance on sport. Additionally, Downey (2005) conducted a study that investigated the adjustment process of freshmen studentathletes and non-athletes at a large NCAA Division I university and used the Student Adaptation to College Questionnaire (SACQ) Baker and Siryk (1999) and a demographic questionnaire to obtain results. Downey (2005) found lower commitment levels and less attachment to the university among student-athletes as compared to non-athletes.

The current study examines differences that are perceived to exist in adjustment to college between the student-athletes and the non-student athletes. The purpose of this study is to discover new ways of improving social adjustment of student-athletes at the Division II level. Specifically, we sought to answer the following questions: What differences exist in social adjustment to college among 
the student-athletes and non-athletes? What differences exist between males and females in social college adjustment? What differences exist across race/ethnicity categories of student-athletes? We hope that by answering these questions, we provide helpful information to athletic departments and institutions that assists them in identifying ways to better support student-athletes as they adapt to college and ultimately increase the retention rate of student-athletes.

\section{THEORETICAL FRAMEWORK}

Tinto's theory (1993) serves as the framework for the study, tying together the areas of student-adjustment and student influences, and has been cited in over 400 studies Braxton et al. (1997). Tinto's Theory of Student Retention, describes the idea of institutional departure, offering that student persist when integrated well into academic and social systems of a higher education institution and can adjust to the college environment through the influences within these systems. If adjustment to college is negative, the overall experience may lead to early institutional departure. Tinto's theory used in this study is presented in figure 1.

As an advocate for improving retention, Tinto (2006) defined three areas to address and implement in higher education. First, the understanding of why students leave and what can be done to make them stay Tinto (2006). Second, implementation of programming, identifying the effective action and implementing it in ways that will enhance student retention Tinto (2006). The third area is the lesson of student income. Low-income students have more access to higher education and gaps in access between low and high-income students have decreased, although a gap still exists between well to-do and poor students in fouryear degree completion Tinto (2006).

Tinto's theory has been modernized and appraised by other authors in recent years to reflect the ever-growing diversity in higher education and also to align with the array of culture in college athletics. While Tinto's theory reflects the framework and scope of this study, it has suffered some criticism from many scholars due to its lack of appropriateness in the study of underrepresented populations, such as minorities (minoritized students). Schutt (1996) was one of many who created an adaptation of the theory. Lyons (2007) used Schutt's adaptation to compare different social integration tools and found it to be highly reliable.

Several authors who specialize in intercollegiate athlete development have referenced Tinto's model as a reliable predictor of student retention. Two researchers analyzed and adapted Tinto's model and modified it to create a conceptual model of their own. Comeaux and Harrison (2011) used precollege characteristics, pre-college commitments, and commitments (after academic and social experiences in the college environment) as a predictor of success in college among student athletes in their own model. As a conceptual adaptation, the model was geared toward assisting student affairs leaders, especially academic advisors and counselors who are committed to developing the academic talents of studentathletes regardless of race, gender, or type of sport Comeaux and Harrison (2011).

\section{METHOD}

A non-experimental, quantitative research design is used in this study to measure the relationship between different variables (race/ethnicity, gender, and sport participation) and examine the responses of study participants. The design is ex post facto, meaning it assessed the current state of relationships among a set of variables rather than manipulating any variables to observe the effects of such 
manipulation. Kumar (2012) supports that quantitative study designs have typically been tested for reliability and validity and are well structured and specific.

For this particular study, the results of social adjustment among studentathletes and non-athletes are examined and analyzed to identify best practices for improving social adjustment. While several divisions exist within the (NCAA) (2016), the researcher had easy access to students (athletes and non-athletes) from the selected schools, thus giving the sample a convenience sample aspect. In addition to its convenience aspect for this study, Division II athletes served the study well because they are scholarship eligible (unlike Division III athletes) and they participate in a high level of competition, while not receiving as much media exposure and popularity as Division I athletes.

In this quantitative research design, survey method was used to collect data. Surveys can often have a rapid turnaround and also have the advantage of identifying attributes of a large group from a small sample (Creswell, 2009). It also allows the researcher to collect the data at a distance, through email or other online sources. Suter (2006) suggests that survey responses are easily prone to respondent bias and individuals can choose not to respond causes lower response rates than preferred. One example might be the student who reports a higher level of social adjustment than they are actually achieving. However, a disadvantage could be the lack of descriptive information found in other forms of research design, such as qualitative or mixed methods.

SACQ is designed to be given in paper format. After receiving approval from Western Psychological Services (WPS), researchers put the questionnaire into Qualtrics so that it could be delivered electronically. One of the functions of this online survey platform, used by the researchers, is the ability to ensure surveys are only completed by those who have read and agreed to the consent form.

Before any research took place, researchers had ethical research training. IRB applications were approved for the researchers' home institution as well as the two participating institutions. An implied consent form appeared in the email before the participant was able to take the survey. The form was the standard "participant information form" provided by OSU IRB. Once the individual agreed to the consent form, they were able to take the survey. Participant information and responses remained confidential as names of the individuals were not exposed.

\section{PROCEDURES}

This study used convenience sampling that included students from two research sites in four-year regional universities in Oklahoma. The researcher had been employed at both institutions and knew personnel as a result. Participants were recruited through face-to-face interactions and emails with instructors, and academic and athletic advisors. These personnel in turn assisted the researcher in sending out the surveys through the campus email system.

Participant confidentiality was implemented to keep the results biased free, as it allowed them to answer freely (or not answer) without consequence. The researcher did not report the results of the surveys to instructors, coaches, or any other University personnel. University personnel had no way of knowing who completed the survey, as the participants were not identified.

\section{PARTICIPANTS}

A total of 215 surveys were distributed to student-athletes and non-athletes from two regional (division II) universities in Oklahoma. The sample size was 
chosen due to the small subgroup typically used in the higher education population (Wiersma \& Jurs, 2005). This research study did not have external or internal grant funding and was limited in distribution due to the cost factor. Of the 215 surveys distributed, 138 completed surveys were analyzed. Results show 85 studentathletes, and 53 non-athletes completed the social subscale of the SACQ. 95 participants self-identified as Caucasian Melendez (2006) classified this group as majority) while 43 identified as "other" Melendez (2006) classified this group as minoritized). 65 males and 73 females completed the social subscale portion.

Advisors and instructors distributed the surveys at their discretion. Survey results do not claim to represent the racial and gender representation in the institutions. Any enrolled student, classified at any level, freshman or graduate, could participate in the study. Because the study was conducted at two institutions with convenient access to the researcher, the findings did not generalize to the entire population of student-athletes and non-athletes.

\section{INSTRUMENTATION}

This study used the SACQ and a brief researcher-developed demographic questionnaire to collect data. The demographic questionnaire was distributed as part of the survey to gather measures regarding participants' gender, age, race/ethnicity, academic classification, parents' education, sport, scholarship status (scholarship or non-scholarship athlete), and competitive college sports participation. Demographic information supports the study in gathering the background of each participant to be included in the data analysis. The demographic section was consistent with the Melendez (2006) survey, and these variables have been predictors of college adjustment in literature.

The SACQ was designed by Robert W. Baker and Bohhan Siryk in 1987 and was published by Western Psychological Services (WPS) in 1989 (see Appendix A). The SACQ is a commonly utilized instrument for evaluating the adjustment of college students regarding student retention and psychological well-being (SACQ, 1989). The SACQ is more reliable than other instruments used to measure similar variables (SACQ, 1989). Beyers and Goossens (2002) tested the SACQ for concurrent and predictive validity in a study, as the instrument measured the differences between European and North American systems of higher education. After analyzing data, Beyers and Goosens (2002) found the instrument to be reliable and valid, and discovered that the subscales (e.i. social subscale) of the SACQ make a more distinctive contribution when measuring college adjustment. Hutt (2012) also used the SACQ and discovered a relationship between psychological and environmental influences and student retention. Ostrove and Long (2007) also found the SACQ instrument to be highly reliable in a study measuring the effects of social class on college adjustment, finding that while social class did exist as a factor of college adjustment, the social and academic experiences allowed for a sense of belonging for students of all social classes.

For the current study, the researcher sampled students in all undergraduate academic levels (freshmen, sophomores, juniors, seniors, and graduate students). WPS states that the SACQ is appropriate for use with students at any time during their undergraduate career. As scores are analyzed, higher scores result in stronger levels of adjustment. The SACQ is considered a multi-dimensional instrument which allows students to respond utilizing a 9-point Likert-type scale anchored by the roots (1) "applies very closely to me" to (9) "doesn't apply to me at all." This amount of detail helps identify the adjustment levels for participants at each area of adjustment. The entire instrument (all subscales) consists of 67 items. There are 
four subscales: social, academic, personal-emotional, and attachment to the institution (SACQ manual, 1999).

For this publication, researchers as only reporting the social adjustment subscale scores were collected and analyzed to examine social adjustment. The Social Adjustment subscale (20 items) measured the student's success in coping with the interpersonal-societal demands inherent in the college experience (SACQ manual, 1999). The social adjustment subscale measures a student's success in coping with the interpersonal-societal demands inherent in the college experience (SACQ manual, 1999).

There are four sections of questions in the social adjustment subscale: general (7 items), other people (7 items), nostalgia (3 items), and social environment (3 items) (SACQ manual, 1999). For example, one question is "I feel that I have enough social skills to get along well in the college setting," on which each participant selfreported on the 9-point Likert-type scale from a (1) "applies very closely to me" to (9) "doesn't apply to me at all."

A brief researcher-developed questionnaire was distributed as part of the survey to gather measures regarding participants' gender, age, race/ethnicity, academic classification, parents' education, sport, scholarship status (scholarship or non-scholarship athlete), and competitive college sports participation. Demographic information supports the study in gathering the background of each participant to be included in the data analysis. The demographic section was consistent with the Melendez (2006) survey, and these variables have been predictors of college adjustment in literature.

\section{DATA ANALYSIS}

Data analyses were conducted through $t$-tests and chi-square analyses which measured the differences among participants, and an ANOVA was conducted for the SACQ social subscale and compared to the variable groups. SPSS software was used to analyze the data.

\section{RESULTS}

The social adjustment subscale measures a student's success in coping with the interpersonal-societal demands inherent in the college experience (SACQ manual, 1999). Lower scores are associated with low social adjustment, while higher scores represent high social adjustment. For the social subscale portion of the survey, 138 responses were analyzed. As shown in table 1, 85 athletes, 53 non athletes, 65 males, and 73 females completed the social adjustment survey.

Table 2 presents the results of the relationship between minoritized and majority groups and the scale. The results of ethnicity showed a difference in social adjustment, with the minoritized group scoring higher (94.19) than the majority group (88.43). This group (minoritized -majority) also had a p-value ( $p=.022$ ) which showed significant main effects.

Analysis of Variance tests (ANOVAs) were used to compare scores on social adjustment across groups based on athletic participation and gender. Table 3 presents the ANOVA table for the social adjustment subscale and interaction in the $2 \times 2$ design. Data in the table provides a sum of squares, degrees of freedom, mean square, F-values, and significance for the ANOVA used to test the interactions and main effects. The results show a significant main effect for athlete vs. non-athlete ( $p$ $=.002)$ and gender $(p=.011)$. In addition, the student-athlete/non-athlete and gender category interacting together scored a marginal p-value score of .056. 
Concerning participant status as an athlete or non-athlete, non-athletes scored higher in social adjustment (94.79) compared to the athletes (87.38). In addition, an ANOVA used show a significant main effect for athlete vs. non-athlete $(p=.002)$. This outcome resulted in a large difference between the two groups.

Social scores among genders showed females scoring slightly higher (91.48) than males (88.81). The ANOVA also showed main effects among the groups $(p=$ .011). In summary, female non-athletes who were of minoritized subgroup had the overall highest scores.

\section{DISCUSSION OF FINDINGS}

The results of the study suggest differences existed within the SACQ social subscale of college adjustment among the group variables: athletic participation, gender, and race. Because additional information was not collected from the participants using qualitative or other research methods, it cannot be determined why differences exist. Perhaps the most important finding of this particular study is that the differences existed in terms of athletic participation, gender, and race. The researchers submit these areas for further exploration, as this was only a onetime study and could not generalize the entire population of students, in the areas of athletic participation, gender, and race.

The high adjustment scores of non-athletes who were female might indicate that that group was well adjusted socially. While adjusting can be hard, studentathletes have opportunities to make new friends that they may not have made if they were on a team or paired with those individuals in competition. Being on an athletic team could form more cohesion among student-athletes than their non-athlete peers. There has been research that college males struggle, which could indicate a lack of engagement of college men in student affairs and academic affairs program and services Ayres (2007). It would be interesting to understand which (if any) of the individuals in either group were involved in a campus organization, which would add another layer of social interaction.

One indicator of high scores in athletes could be the level of play (Division II) within this group, allowing for more personal interaction to peers compared to bigger (Division I) institutions. The size of the institution could also play a factor in the level of adjustment among minoritized students, allowing for more interaction in a smaller environment. While the researchers can speculate to why certain groups scored higher in social adjustment, more research is needed to help narrow down possible reasons for these high scores, and to identify any trends in future studies, specifically in the Division II institutions.

Similar to the current study, Melendez (2006) discovered that social factors played an important role in the student-athlete experience, as student-athletes scored higher on social adjustment than non-athletes. However, Melendez (2006) did not measure upperclassmen (juniors and seniors), unlike the current study which had approximately $60 \%$ upperclassmen participants. It is not known what differences might exist between underclassmen and upperclassmen. Leadership could be a factor in this area of adjustment as personal (student-to-student) interaction is associated with leadership Astin (1993).

Tinto's theory played an important role in the current study, which supports this model as a predictor of student adjustment. However, Tinto's model does not reflect the importance of the specific type of institution in which it is applied, as this study only measured adjustment in Division II athletes. More research in larger Division I institutions may have different outcomes as related to Tinto's model, due to different institutional experiences (formal and informal) existing that is related 
to student persistence at each level. Additionally, it's possible that the pre-entry attributes (family background, skills and abilities, and prior schooling) aspect of Tinto's model could be different in smaller Institutions, which could alter levels of achievement in each area and also be reliant on geographical factors.

\section{LIMITATIONS}

This study had a few limitations. The first limitation was the difficulty in obtaining surveys responses. The surveys were sent out through campus email at the two universities with assistance from the athletic and academic departments. However, the target number of 200 participants were not met, as 138 completed the survey.

The second limitation was the use of the departments to help distribute the surveys. This could have created a small amount of bias, as the student-participants were encouraged several times by faculty and coaches to complete this survey. This could have made the participants feel obligated to take the surveys.

The third and final limitation is the design and type of survey. The survey is based on Tinto's theory of student retention. It did not address other theories that might have application. The study did not include off-campus activities or jobs, could be a contributing factor. This could talk more about exactly what factors are making the student stressed, and how it could be affecting their academic, social, or emotional adjustment. Another factor could be the timeframe in which the data was collected. Students were asked to take this survey at the beginning of the spring semester (after winter break), which could have contributed to their current feelings of adjustment. Perhaps asking participants to take the surveys at a different point of the semester may have altered the responses.

\section{IMPLICATIONS AND RECOMMENDATIONS}

The level of adjustment, affected by the overall college experience, can influence the decisions of student departure Tinto (1993). Different aspects of faculty teaching role performance, such as active learning and classroom size may serve as a factor of Tinto's Theory, as classroom behaviors could play a role in the social and academic integration of students inevitably leading to departure decisions Braxton et al. (2000). These different aspects were not measured in this study, and as a result it is unknown whether or not it influenced the results.

A deeper examination of the various social activities, such as membership in campus organizations might shed light into why these differences may occur. How these experiences might contribute to social adjustment would be an excellent future research study. Specifically, academic and social interactions should be more closely examined to determine what needs exist.

Support systems exist within a university for various subgroups, such as athletes. For example, student-athletes are required to maintain a higher GPA and often academic centers exist to help remediate if needed. Potential research questions might include how often athletes access those centers. Campus administrators could use this information to help students of all classifications to transition in this stressful time in life and make the experience more enjoyable.

Other research has indicated a relationship between institutional attachment and social adjustment. Baker and Siryk (1989). Particularly for the present study, all sub-samples (or groups) scored low in institutional attachment. Students who struggle with being away from home score low on social adjustment and institutional attachment scales and likely to leave school before graduation Baker 
and Siryk (1989). This would call for more research in the role attachment plays on student-adjustment. Perhaps research on post-graduates' experiences and/or exit interviews with departing students would give an idea of what strategies were successful for retention.

Different populations of students, such as community/junior colleges and bigger four-year (Division I) institutions, could be researched to get a better understanding of college adjustment in all academic environments. Another option could be to examine more than two universities to get a stronger response rate, with a wider range of students at different locations. Specifically, different states would give a better idea of college adjustment in students across the nation and might add more generalizability to the study. In addition, more data on international students as compared to residential students would be interesting to explore and compare.

A different methodology could be considered as well. This study was a nonexperimental quantitative study. Use of qualitative methods could give a more descriptive analysis of the college experience and would add a richer understanding to this topic. Personal interviews with college students and student-athletes could be conducted with a smaller sample size to add a layer of personal interaction to the research. With more time to collect results, an ethnography could be useful and gain a first-hand analysis of the topic. Ethnographies are useful in qualitative research as it allows the researcher to embed themselves in the environment, allowing the readers to feel a "real life" aspect of the study (Creswell, 2009). An ethnography would prove a natural setting for the researcher to evaluate the specific surroundings.

For some individuals, one certain area of college could be the one factor that influences a student's decision to leave or stay. Lack of satisfaction in college could be related to any number of academic, social, or personal/emotional issues. As a former academic advisor for athletics, the researcher has seen firsthand dropout that happens when a student-athlete is not well adjusted. In some cases, studentathlete simply leave college as soon as athletic eligibility is exhausted. A better understanding of what we can do to make the experience better might prevent this phenomenon from occurring.

It is important to understand how we can positively affect our students and be alert to and appropriately respond when changes in student behavior are observed. A positive classroom experience can improve the integration of a student. By encouraging social interaction in addition to academic-related aspects of the college experience, we can increase student adjustment as well as overall institutional attachment. Colleges and Universities are encouraged to build positive relationships with their students and promote higher quality support programs that could make a better experience for college students and prevent student attrition. By providing activities and support programs, such as open forums and peer mentoring, studentathletes could become more comfortable and self-confident, thus making them more adjusted on a social aspect of college.

\section{CONCLUSION}

In the current study, levels of social adjustment were measured among studentathletes and non-athletes, between gender and race. The study found that female non-athlete minoritized students scored highest on the social adjustment subscale. Continued investigation into the phenomenon of students who are also athletes might yield valuable information for all concerned. The more we know about the needs of students, the better positioned university personnel would be to handle 
social, academic, personal/emotional, and attachment issues, such as those in Tinto's model.

Colleges and universities are encouraged to build positive relationships with their students and promote higher quality support programs that could make a better experience for college students and prevent student attrition. Social adjustment to college is complex and faculty members who recognize its complexity could help student attrition. Retention and completion to graduation is the ultimate goal for all students regardless of status.

\section{REFERENCES}

Astin, A. (1993). What matters in college ? San Francisco, CA : Jossey-Bass.

Ayres, A. R. (2007). College student adaptability and greek membership : A single institution case study (Order No. 3276420). Available from ProQuest Dissertations \& Theses Global. (304815190). Retrieved from http://argo.library.okstate.edu/login?url=https://searchproquestcom.argo.library.okstate.edu/docview/304815190?accountid=41 17

Baker, R. W., \& Siryk, B. (1989). Student adaptation to college questionnaire (SACQ). Los Angeles, CA : Western Psychological Services.

Baker, R. W., \& Siryk, B. (1999). SACQ : Student adaptation to college questionnaire : Manual. Western Psychological Services.

Braxton, J. M., Milem, J. F., \& Sullivan, A. S. (2000). The influence of active learning on the college student departure process : Toward a revision of Tinto's theory. The Journal of Higher Education, 71(5), 569-590. Retrieved from https://doi.org/10.1080/00221546.2000.11778853

Braxton, J. M., Sullivan, A. S., \& Johnson, R. M. (1997). Appraising Tinto's theory of college student departure. In J. C. Smart (Ed.), Higher education: Handbook of theory and research (Vol. 12 pp. 107-164). NY : Agathon.Braxton, J., Milem, J., \& Sullivan, A. (2000). The Influence of Active Learning on the College Student Departure Process : Toward a Revision of Tinto's Theory. The Journal of Higher Education, 71(5), 569-590. doi :10.2307/2649260 Retrieved from https://doi.org/10.2307/2649260

Brewer, B. W., Van Raalte, J. L., \& Linder, D. E. (1993). Athletic identity: Hercules'muscles or Achilles heel? International Journal of Sport Psychology, 24, 237-254. Retrieved from https://doi.org/10.1037/t15488000

Carodine, K., Almond, K. F., \& Gratto, K. K. (2001). College student athlete success both in and out of the classroom. New Directions For Student Services, 2001(93), 19. Retrieved from https://doi.org/10.1002/ss.2

Comeaux, E., \& Harrison, C. K. (2011). A Conceptual Model of Academic Success for Student-Athletes. Educational Researcher, 40(5), 235-245. Retrieved from https://doi.org/10.3102/0013189X11415260

Downey, V. P. (2005). An exploration of the adjustment processes of freshmen student athletes and non -athlete students (Order No. 3170911). Available from ProQuest Dissertations \& Theses Global. (305383994). Retrieved from http://argo.library.okstate.edu/login?url=http://search.proquest.com.argo .library.o kstate.edu/docview/305383994 ?accountid=4117 Retrieved from https://www.proquest.com/openview/b2bfe90efa05812bb674d4d2bd6c 4ebd/1?pq-origsite $=$ gscholar \&cbl=18750\&diss $=y$ 
Freeman, S. L. (2009). An exploration of the relationships between the quality of the sport, social, and academic experiences of college student -athletes and their adjustment to college : A qualitative analysis (Order No. 3394151). Available from ProQuest Dissertations \& Theses Global. (304996558). Retrieved from http://argo.library.okstate.edu/login?url=http://search.proquest.com.argo .library.o kstate.edu/docview/304996558 ?accountid=4117

Jordan, J. M., \& Denson, E. L. (1990). Student services for athletes: A model for enhancing the student-athlete experience. Journal of Counseling \& Development, 69(1), 95-97. Retrieved from https://doi.org/10.1002/j.1556-6676.1990.tb01467.x

Kurtz, J. E., Puher, M. A., \& Cross, N. A. (2012). Prospective prediction of college adjustment using self-and informant-rated personality traits. Journal of personality assessment, 94(6), 630-637. Retrieved from https://doi.org/10.1080/00223891.2012.672506

Lyons, A. L. (2007). Assessment of Social and Academic Integration Among Track and Field Student-Athletes of the Atlantic Coast Conference.

McFarlane, A. (2014). An Examination of the Role that Academic, Athletic, and Social Integration Play in the First-Year Freshman Student Athlete Experience.

Melendez, M. C. (2006). The influence of athletic participation on the college adjustment of freshmen and sophomore student athletes. Journal of College Student Retention: Research, Theory \& Practice, 8(1), 39-55. Retrieved from https://doi.org/10.2190/8GLY-G974-V7FM-E1YD

National Collegiate Athletic Association (NCAA). (2016). About the NCAA. Retrieved from http://www.ncaa.org.

National Collegiate Athletic Association. (2013). Student-athlete participation : 1981-1982 - 2012-13. Indianapolis, IN : National Collegiate Athletic Association.

National Collegiate Athletic Association. (2016). 2015-2016 NCAA Division II Manual. Indianapolis, IN : National Collegiate Athletic Association.

Nguyen, A. N., \& Taylor, J. (2003). Post-high school choices: New evidence from a multinomial logit model. Journal of Population Economics, 16(2), 287-306. Retrieved from https://doi.org/10.1007/s001480300149

Ostrove, J. M., \& Long, S. M. (2007). Social class and belonging: Implications for college adjustment. The Review of Higher Education, 30(4), 363-389. Retrieved from https://doi.org/10.1353/rhe.2007.0028

Schutt, D. A., Jr. (1996). An expansion of Tinto's model to include student-athletes: A study of an exploratory measure (Order No. 9640015). Available from ProQuest Dissertations \& Theses Global. (304244518). Retrieved from http://argo.library.okstate.edu/login?url=http://search.proquest.com.argo .library.o kstate.edu/docview/304244518 ?accountid=4117

Suter, W. (2006). Introduction to Educational Research : A Critical Thinking Approach. Sage Publications.

Thomas, L. (2002). Student retention in higher education: the role of institutional habitus. Journal of Education Policy, 17(4), 423-442. Retrieved from https://doi.org/10.1080/02680930210140257

Tinto, V. (1975). Dropout from higher education: A theoretical synthesis of recent research. Review of educational research, 89-125. Retrieved from https://doi.org/10.3102/00346543045001089 
Tinto, V. (1987). Leaving college : Rethinking the causes and cures of college attrition. Chicago, IL : University of Chicago Press. UNESCO Education for All (2001).

Tinto, V. (1993). Leaving college : Rethinking the causes and cures of student attrition. Chicago : The University of Chicago Press. Retrieved from https://doi.org/10.7208/chicago/9780226922461.001.0001

Tinto, V. (2006). Research and practice of student retention : What next ? Journal of College Student Retention, 8(1), 1-19 Retrieved from https://doi.org/10.2190/4YNU-4TMB-22DJ-AN4W 